\title{
In the mood to face the facts: When a positive mood promotes systematic processing of self-threatening information
}

\author{
Enny Das · Bob M. Fennis
}

Published online: 13 June 2008

(C) The Author(s) 2008

\begin{abstract}
Two experiments tested the hypothesis that a positive mood can increase attendance to, and systematic processing of, threatening health information, particularly when the information is self-relevant. In Study 1, a positive mood increased differentiation between strong and weak arguments in a threatening health message about RSI only for participants who had received false feedback regarding their high vulnerability to RSI. Mood had no effects under conditions of low vulnerability. In Study 2, a positive mood speeded up responses to self-threatening words-compared with neutral words-for smokers who had just read a threatening health message about smoking. The authors conclude that fostering a positive mood may promote attendance to and systematic processing of information that threatens the self, and hence contribute to the success of health campaigns targeted at individuals who are vulnerable to specific health risks.
\end{abstract}

Keywords Mood · Vulnerability · Information processing $\cdot$ Threatening health message $\cdot$ Persuasion

\section{Introduction}

I can't seem to face up to the facts

I'm tense and nervous and I can't relax"-David Byrne (Talking Heads)

E. Das $(\bowtie)$

Department of Communication Science, Faculty of Social

Sciences, VU University, De Boelelaan 1081, 1081 HV

Amsterdam, The Netherlands

e-mail: ehhj.das@fsw.vu.nl

B. M. Fennis

Department of Social and Organizational Psychology,

Utrecht University, Utrecht, The Netherlands
Mood has a profound impact on the way people perceive the world around them. Over the years, mood has been shown to affect memory processes (e.g., Schwarz and Clore 1996), judgment and decision-making (e.g., Clore et al. 1994; Forgas 1995, 2000; Sinclair and Mark 1992), and persuasion (e.g., Bless et al. 1990; Wegener et al. 1995). Mood also affects the strategies people use when processing incoming information. In general, positive moods appear to promote global, flexible, intuitive and holistic information processing (see Isen 1999, 2004 for overviews). Negative moods, in contrast, have been associated with more systematic, narrow, focused, and analytic forms of processing (see Schwarz and Clore 1996 for a review).

Mood does not, however, produce consistent main effects on information processing. On the contrary, the effects of mood appear flexible, and context dependent. For instance, the effects of mood may be moderated by the personal interpretation of its implications (Martin and Stoner 1996; Martin et al. 1993), and by situational demands (e.g., Abele et al. 2005; Baumann and Kuhl 2005). Furthermore, the effects of mood on information processing appear to vary with message valence. According to the hedonic contingency view of mood, people generally strive to maintain, or attain positive mood states (Wegener and Petty 1994). In positive mood states, people are most likely to attend to information that is hedonically rewarding, i.e. messages that contain uplifting and positive information, and least likely to attend to messages that may spoil a good mood. A positive mood is thus proposed to induce systematic processing of uplifting messages, and heuristic processing of aversive, unpleasant messages (Wegener et al. 1995). In a negative mood, information processing will be much less contingent on the hedonic consequences of a message, simply because negative moods are more likely to improve regardless of message content. In general, 
empirical studies have supported hedonic contingency assumptions (see Hullett 2005, for a meta-analysis).

Nevertheless, recent findings suggest that a positive mood may promote systematic processing of negative information when the information is relevant to the self (Raghunathan and Trope 2002). At first glance, these findings appear at odds with hedonic contingency assumptions. Clearly, there is little hedonic reward in facing negative or even threatening facts about the self. These findings thus suggest that there are instances where a positive mood does not promote a hedonic pursuit of pleasure, but rather attunes individuals to 'face up to the facts'. In the next section, we discuss this particular function of mood, and the moderating role of self-relevance in more detail.

\section{Mood and self-threatening information}

People are generally reluctant to face unpleasant, self-relevant facts. For instance, people tend to downplay unfavorable feedback about their personalities by conjuring up reasons that undermine the accuracy of the feedback (e.g., Ditto and Lopez 1992; Trope et al. 2001; Trope and Neter 1994). Similarly, receivers of threatening health messages often trivialize the personal relevance of the information, minimize the seriousness of a health risk, or engage in wishful thinking (e.g., Das et al. 2003; Jemmott et al. 1986). From a self-regulation perspective, such responses serve an important function: they protect an individual against negative emotions such as fear, anxiety, and depression (Aspinwall 1998; Raghunathan and Trope 2002; Trope and Neter 1994; Trope and Fishbach 2000), and help to maintain a positive self-image (e.g., Reed and Aspinwall 1998; Sherman et al. 2000). Nevertheless, not facing the facts can be a problem, particularly in the health domain, where persuasive messages are designed to prevent illness. Hence, recent research efforts have focused on strategies that make individuals more accepting of aversive yet self-relevant information.

One strategy that appears to increase acceptance of selfthreatening information is the induction of a positive mood. Specifically, a positive mood may increase relative interest in negative feedback about the self, thus attenuating a global preference for positive feedback (Trope and Pomerantz 1998). In addition, a positive mood increased interest in feedback about individual weaknesses only when the information was relevant to a self-related goal (Gervey et al. 2005). Of particular relevance to the present study, the induction of a positive mood enhanced persuasion regarding a message that described the harmful effects of caffeine intake only when the information was relevant to the self, i.e. only for caffeine consumers (Raghunathan and Trope 2002). When the information was not relevant to the self, a positive mood had no effects on persuasion.
With respect to information processing, the effects of a positive mood may also be moderated by self-relevance. When an aversive message is irrelevant to the self, systematic message processing has personal costs, because it spoils a good mood, and no personal benefits, because there are no implications for the self. Accordingly, a positive mood is likely to instigate a pursuit of hedonic concerns, and promote less systematic modes of information processing (Wegener et al. 1995). For messages with high relevance to the self, intensive message processing will entail short-term affective costs (see Raghunathan and Trope 2002 for evidence relevant to this proposition), but also benefit the self in the longer run, e.g. by acquiring valuable information that may help improve an important self-concept (cf. Wegener et al. 1995). In these conditions, a positive mood is likely to promote systematic message processing (Raghunathan and Trope 2002). In short, recent research suggests that individuals may sometimes use a positive mood as a resource to "overcome" the short term affective costs of systematically processing potentially threatening information, in order to acquire longer-term benefits of the information for the self. The precise dynamics of this process, however, have not yet been systematically addressed.

More in particular, solid evidence regarding the interactive effects of self-relevance and mood on information processing has remained lacking (see Trope et al. 2001). According to dual-process models of persuasion (Petty and Wegener 1999), a comprehensive and robust test of information processing would require effects of the quality of the arguments in a persuasive message on two types of dependent measures (Petty and Cacioppo 1986). Specifically, systematic processing is inferred if participants differentiate between strong and weak arguments on attitudes toward a persuasive message (Petty and Wegener 1999). In other words, participants who process a message systematically should agree more with this message to the extent that it contains strong arguments, rather than weak arguments. In addition, systematic message processing manifests itself by the extent and valence of issue-relevant thoughts recipients generate in response to the message, such that recipients should generate more thoughts supportive of message content, and less thoughts discounting message content, to the extent that a message contains strong arguments, rather than weak arguments (Petty and Wegener 1999).

Thus far, interactions between self-relevance, mood and argument quality on thoughts and attitudes toward a threatening message have not been tested empirically. In addition, apart, from the postulated effects of mood on controlled, systematic processing, it is unclear whether the effects of mood also extend to more automatic, implicit forms of information processing. Recent studies suggest that a positive mood promotes access to implicit, intuitive knowledge of what is relevant to the self, in terms of 
general goals, motives, and experiences (Baumann and Kuhl 2003; Bolte et al. 2003; Koole and Kuhl 2003), and attunes individuals to 'the grand scheme of things' (Trope et al. 2001). A positive mood may thus promote access to implicit, intuitive resources needed to judge the self-relevance of incoming information, and, if necessary, switch processing mode (see Baumann and Kuhl 2005 for evidence relevant to this assumption). However, the implicit processes involved in the effects of mood on the acceptance of self-threatening information have received little empirical attention.

The key objective of the present research is thus to extend previous findings by providing robust empirical tests of the cognitive processes involved in the effects of mood on the acceptance of threatening health information in two specific ways. First, the present study provides an explicit test of the interactive effects of self-relevance, mood, and argument quality on cognitive processes and persuasion (Petty and Wegener 1999). Second, the present research extends previous findings by testing implicit responses to self-threatening versus non-threatening information. The central hypothesis that we put forward is that a positive mood will promote both controlled, systematic processing of self-threatening health information (Study 1), as well as automatic, implicit attendance to self-threatening information (Study 2).

\section{Overview and hypotheses}

Two experimental studies were conducted to assess the effects of mood on information processing and acceptance of threatening health messages. In line with previous studies (Raghunathan and Trope 2002), we hypothesized that self-relevance will moderate the effects of mood on the controlled and automatic processing of threatening persuasive messages. Under conditions of high self-relevance (i.e., when vulnerability to a health risk is high), a positive mood was expected to induce explicit systematic message processing, and speed up implicit responses to self-threatening words, compared with neutral words. Under conditions of low self-relevance (i.e., when vulnerability to a health risk is low), a positive mood was expected to promote heuristic message processing, and have no effects of implicit responses to threat.

We manipulated mood by asking participants to recall three positive or three negative experiences from the past (cf. Raghunathan and Trope 2002). Self-relevance was varied by presenting participants with false feedback regarding their vulnerability to a health risk (Study 1), or by self-reported health risk behavior (Study 2). The present research extended previous findings by including multiple measures of information processing. First, we manipulated argument quality in the persuasive messages. Past research has shown that sensitivity to the quality of the arguments in a persuasive message is a reliable indicator of elaborate cognitive processing (Petty and Wegener 1999). Hence, we included this manipulation in order to assess the underlying nature of the cognitive processes that were elicited by our mood and vulnerability manipulations. Second, we included a thought-listing measure that allowed us to assess the number and valence of responses to the health message. Third, we measured response latencies to self-threatening words versus neutral words to assess implicit mood effects. As far as we know, no study has measured implicit responses to threatening versus non-threatening stimuli as a function of mood.

\section{Study 1}

Study 1 manipulated both self-relevance and mood in one design and assessed their additive and interactive effects on information processing. Based on dual-process models of persuasion, this study assessed message elaboration, i.e., the extent to which participants engage in systematic processing, in two ways: (1) we manipulated argument quality in a health message in order to assess message elaboration, and (2) assessed the number and profile of issue-relevant thoughts (cf. Petty and Wegener 1999). We predicted that a positive mood would increase sensitivity to the quality of the arguments in a health message only when this information is self-relevant, i.e., under conditions of high personal vulnerability to a health risk, and thus increase persuasion for strong arguments, and decrease persuasion for weak arguments. In contrast, under conditions of low vulnerability, a positive mood was expected to induce heuristic processing, and thus decrease a differentiation between strong and weak arguments.

\section{Method}

\section{Participants and design}

A total of 121 students at a university of a large city participated in the experiment. The sample consisted of 51 male and 70 female participants with a mean age of 22 years $(S D=2.40)$. Participants volunteered and were randomly assigned to experimental conditions. The design was 2 (vulnerability: high vs. low) $\times 2$ (mood: positive vs. negative) $\times 2$ (argument quality of persuasive message: weak vs. strong) between-subjects.

\section{Procedure and independent variables}

As a cover story, participants were told that they would take part in a computerized survey about personal values and 
experiences, Repetitive Strain Injury (RSI) and health. Participants were first presented with a short introduction about RSI and the "Boston RSI Sensitivity Test", and were led to believe that this test measured their risk of developing RSI related health problems in the future on the basis of a personality test. Participants completed the test and were told that the computer analyzed their responses. Next, they received false feedback regarding their vulnerability to RSI on their computer screens. Participants were informed that their risk of developing RSI related health complaints was either quite high (high vulnerability condition), or quite low (low vulnerability condition). Next, participants read a message that described the negative health consequences of RSI (e.g., chronic complaints in arms and hands). This information was held constant across conditions.

Mood was manipulated following the procedure described by Raghunathan and Trope (2002). Participants were asked to recall three positive or negative events they had recently experienced. They were asked to describe each event in a few sentences, indicating in particular the details of the event that made the experience positive or negative for them personally. To boost the credibility of the mood manipulation in the present health context, participants were told that research has shown that personal experiences from the past can have a profound impact on health, and that the present research was designed to further test this possibility. Next, participants were exposed to the persuasive message, which was presented as a letter submitted to a journal of health psychology. The message described RSI prevention training as a way to reduce the risk of experiencing the negative health consequences of RSI, and was supported by five weak or five strong arguments that were selected in a pilot study (cf. Petty and Cacioppo 1986). Examples are: "Research has demonstrated that knowledge of RSI-prevention strategies improved physical and psychological well-being" (strong argument), and "The institute that developed the RSIprevention training would not put the training on the market unless it was effective" (weak argument). After reading the health message, participants completed the manipulation checks of vulnerability, mood, and argument quality, and the thought-listing and attitude measures (in this order). At the end of the experiment, participants were thanked for their participation and were extensively debriefed, in order to make sure that they understood real purpose of the experiment. None of the participants guessed the real purpose of the experiment, or expressed any suspicion regarding the experimental procedure.

\section{Manipulation checks}

Six items assessed the effectiveness of the vulnerability manipulation on a 7-point scale. Examples are: "The chance that I will develop RSI related health problems is high" and "Due to my sensitivity to RSI I am more prone to RSI related health problems" (Cronbach's alpha $=.90)$. The effectiveness of the mood manipulation was assessed by 9 items from the Profile of Mood State (POMS, Wald 1984), measuring the extent to which participants felt specific emotional states, such as feelings of depression, and relaxation. Negative items were reverse-scored; higher scores yield more positive moods (Cronbach's alpha $=.75$, see Wald 1984 for a complete listing of the items). Three items assessed perceived argument quality of the health message, measuring on a 7-point scale how strong, supportive and sensible participants rated the arguments (Cronbach's alpha $=.88$ ). Correlations between manipulation checks did not differ as a function of experimental manipulations.

\section{Dependent measures}

Cognitive Processing. Participants completed a thoughtlisting task, in which they were asked to write down the thoughts that came to mind while reading the health message (cf. Petty and Cacioppo 1986). No time limit was set; participants could take all the time they needed. Two independent judges categorized issue-relevant thoughts in thoughts confirming (Range $0-4$; Kappa $=.72$ ) message content, e.g., "I am definitely interested in a RSI prevention training" or "I never knew RSI was that serious", and thoughts discounting message content, e.g., "I feel the risk of RSI is exaggerated in this message" or "I am not convinced about the benefits of the proposed RSI prevention training" (Range $0-4$; Kappa $=.71$ ), and neutral thoughts, e.g., "The text reminded me of a book I read some time ago" (Range 0-3; Kappa $=.70$ ). Disagreements between judges were solved through discussion. Issue-irrelevant thoughts were not analyzed (9\% of total; cf. Petty and Wegener 1999). Confirming thoughts correlated negatively with discounting thoughts, $r=-.28, p<.01$, and with neutral thoughts, $r=-.18, p<.05$. Discounting thoughts also correlated negatively with neutral thoughts, $r=-.26, p<.01$.

A thought-listing index was created (cf. Sherman et al. 2000) using the following formula: (confirming issue-relevant thoughts +1$) /($ total issue-relevant thoughts +1$)$. Index-scores that approach 1 indicate higher levels of agreement with the health message; scores that approach 0 indicate lower levels of agreement.

Attitudes. Participants' attitudes toward RSI-prevention training were assessed by a semantic differential scale with 4 items, using a 7-point scale, including how valuable, and interesting participants thought this training was (Cronbach's alpha $=.76$ ). Attitudes were significantly correlated with the thought-listing index, $r=.45, p<.001$, and correlations did not differ as a function of experimental manipulations. 
Results

\section{Manipulation checks}

The manipulation checks of mood and vulnerability were subjected to a 2 (vulnerability: low vs. high) $\times 2$ (mood: positive vs. negative) analysis of variance (ANOVA), to ascertain that the manipulations of vulnerability and mood were successful in producing the intended effects without producing unwanted side effects. The $2 \times 2$ ANOVA on the manipulation check for vulnerability revealed the expected main effect for vulnerability, $F(1,117)=15.74$, $p<.001$. Participants in the high vulnerability conditions felt more vulnerable to RSI $(M=3.65, S D=1.48)$ than participants in the low vulnerability conditions $(M=2.65$, $S D=1.24)$. Mood did not affect perceptions of vulnerability to RSI, either as a main effect, $F(1,117)=2.69$, $p>.10$, or in interaction with the vulnerability manipulation $(F<1)$. A similar ANOVA on the mood-measure revealed a main effect for $\operatorname{mood}, F(1,117)=4.38$, $p<.05$. Participants in the positive mood condition reported a more positive mood $(M=3.37, S D=.49)$ than participants in the negative mood condition $(M=3.13$, $S D=.76)$. Vulnerability did not significantly affect mood, either as a main effect $(F<1)$ or in interaction with the mood manipulation $(F<2)$. A one-way ANOVA on the manipulation check of perceived argument quality revealed that, as expected, arguments were perceived as stronger in the strong arguments condition $(M=4.30, S D=1.24)$ than in the weak arguments condition $(M=3.70$, $S D=1.28 ; F(1,119)=6.93, p<.01)$. In sum, these results confirm that the manipulations of mood, vulnerability and argument quality were successful.

\section{Dependent measures}

Thought-listing. A 2 (vulnerability) $\times 2$ (mood) $\times 2$ (argument quality) ANOVA on the thought-listing index revealed a significant main effect for vulnerability, $F(1$, $113)=8.88, p=.004$, and a significant main effect for mood, $F(1,113)=3.88, p=.05$. Overall, participants had a more positive thought valence under conditions of high $(M=.65, S D=.29)$ compared with low vulnerability $(M=.52, S D=.23)$, and under conditions of positive mood $(M=.63, S D=.26)$, compared with negative mood $(M=.54, S D=.27)$. These main effects were qualified, however, by the hypothesized three-way interaction between vulnerability, mood, and argument quality, $F(1$, $113)=4.83, p<.05$. In line with predictions, simple effects analyses revealed that positive mood affected the extent of systematic processing, as indicated by the increased differentiation between strong and weak arguments on thought valence, only when vulnerability was high $F(1,113)=8.98, p=.003$ (in all other conditions, $F<1)$. Relevant means are displayed in Table 1.

Attitudes. A 2 (vulnerability) $\times 2$ (mood) $\times 2$ (argument quality) ANOVA on the attitude toward RSI management training again revealed a three-way interaction between vulnerability, mood, and argument quality, $F(1,113)=4.58, p<.05$. Similar to the results for the thought listing task, simple main effects analyses again revealed a differentiation between strong and weak arguments for positive mood participants, but only under conditions of high vulnerability, $F(1,113)=4.48, p<.05$ (in all other conditions, $F<1$ ). Relevant means are displayed in Table 1. In sum, only participants in high vulnerability, positive mood conditions reported more positive thoughts and more positive attitudes toward the recommendation when argument quality was strong rather than weak. This sensitivity to argument quality was not observed in low vulnerability, and negative mood conditions.

\section{Discussion}

The present findings support the hypothesis that a positive mood increases systematic processing of a threatening health message, particularly when the information is relevant to the self. When participants felt vulnerable to a health risk, i.e., under conditions of high self-relevance, a positive mood increased sensitivity to the quality of the arguments in the health message. This increased differentiation between strong and weak arguments is a reliable indicator of systematic message processing (Petty and Wegener 1999), and was observed on high vulnerability participants' thoughts and attitudes regarding the health message. In contrast, when a health message was not relevant to the self, mood had no effects on information

Table 1 Interactive effects of vulnerability, mood, and argument quality on thought-listing index and attitudes (Experiment 1)

\begin{tabular}{|c|c|c|c|c|}
\hline \multirow[t]{3}{*}{ Condition } & \multirow{2}{*}{\multicolumn{2}{|c|}{$\frac{\text { Thought-listing }}{\text { Argument quality }}$}} & \multirow{2}{*}{\multicolumn{2}{|c|}{$\frac{\text { Attitudes }}{\text { Argument quality }}$}} \\
\hline & & & & \\
\hline & Weak & Strong & Weak & Strong \\
\hline
\end{tabular}

Low vulnerability

Negative mood $0.51(0.29) \quad 0.52(0.20) \quad 4.42(0.94) \quad 4.64$ (1.37)

$\begin{array}{lllll}\text { Positive mood } & 0.56(0.27) & 0.49(0.12) & 4.39(0.85) & 4.10(1.30)\end{array}$

High vulnerability

Negative mood $0.59(0.29) \quad 0.55(0.31) \quad 4.80(1.07) \quad 4.52(0.95)$

$\begin{array}{lllll}\text { Positive mood } 0.60(0.27) & 0.88(0.17)^{* *} 4.32(0.88) & 5.15(0.87)^{*}\end{array}$

Note: Significant differences (rows) indicate that participants differentiated between weak and strong arguments in the action recommendation

$* p<.05 ; * * p<.01$ 
processing or persuasion (also see Das et al. 2003; De Hoog et al. 2005). These findings are a first demonstration that the effects of mood on the processing of self-threatening information are moderated by self-relevance. When a threatening message is relevant to the self, a positive mood may help receivers to 'face the facts', and engage in systematic processing. When a threatening message has no direct self-relevance, a positive mood is likely to promote hedonic concerns, and prompt heuristic message processing.

\section{Study 2}

Study 1 showed how a positive mood affects explicit cognitive responses to self-threatening information, and enhances the use of deliberate, systematic processing strategies. Study 2 was designed to assess whether these effects extend to the realm of less controlled, automatic processes, and to gain more insight into implicit responses to self-relevant versus self-irrelevant health information. It was hypothesized that the proposed resource function of positive mood may also work at the implicit level, and promote attendance to self-relevant information but not to self-irrelevant information. Under negative mood conditions, this differentiation between self-relevant versus irrelevant information was not expected to occur, because individuals were hypothesized to lack the resources needed to increase differential responding to potentially self-relevant incoming information.

\section{Method}

\section{Participants and design}

A total of 17 men and 15 women with a mean age of 20.66 $(S D=2.42)$ participated in the experiment. All participants were identified as smokers. The design was a mood (positive vs. negative) between subjects and self-relevance (self-threatening vs. neutral) within subjects mixed design.

\section{Procedure and materials}

Participants were told that they would take part in a computerized survey about personal values and experiences, smoking, and health, and were asked to fill out several questions related to their smoking behavior. Next, mood was manipulated by asking participants to recall three positive or negative events they had recently experienced (Raghunathan and Trope 2002). As in Study 1, the credibility of the mood manipulation was boosted by telling participants that research has shown that personal experiences from the past can have a impact on health. Mood was measured immediately after this mood manipulation with 8 items from the Profile of Mood State (POMS, Wald 1984; Cronbach's $\alpha=.80$ ). Participants then read a threatening health message that described the negative health consequences of smoking. The message contained fictitious statements concerning recently discovered serious and severe health consequences of smoking, such as an increased risk of autoimmune diseases, and several types of cancer. The health message was held constant across conditions. Participants then performed a lexical decision task (LDT) that contained the within-subjects manipulation of self-relevance. In this task, participants had to decide as quickly as possible if the target word was an existing word or a nonsense word. The LDT contained 32 neutral words (e.g., house, dog, and holiday), and 60 nonsense words (e.g., grapen, adviering, and din). Most important, however, the LDT also contained 5 self-threatening words from the health message participants had just read, pertaining to the adverse health consequences of smoking (hazardous, danger, death, lung cancer, and risk). All words are single words in the Dutch language (including lung cancer). The self-threatening words were selected on the basis of a pilot study in which participants $(N=30$, smokers, not taking part in the actual experiment) rated on a 7-point scale $(1=$ not at all, $7=$ very much $)$ to what extent these and 10 other words pertained directly to smoking-related health risks. The five words selected were the ones rated highest on this measure $(M=5.71, S D=1.43)$. All words were randomly presented and matched on word length across word type categories. In addition, the pilot study corroborated that there were no a priori differences in response latencies between neutral words and target words $(F<1)$. Response latencies on the LDT for the self-threatening versus neutral words served as our key dependent measure. Upon finishing the LDT, participants were thanked for their participation, debriefed, and dismissed. None of the participants guessed the real purpose of the study.

Results

Mood

A unifactor ANOVA (mood: negative vs. positive mood) revealed the expected main effect for mood condition, $F(1$, $30)=9.18, p=.005$. Participants in the negative mood condition reported more negative moods $(M=6.13$, $S D=.62)$ than participants in the positive mood condition $(M=5.42, S D=.70)$.

\section{Response time analysis}

Type of response (i.e., word or non-word) and response time (in milliseconds) to all LDT words were recorded for 


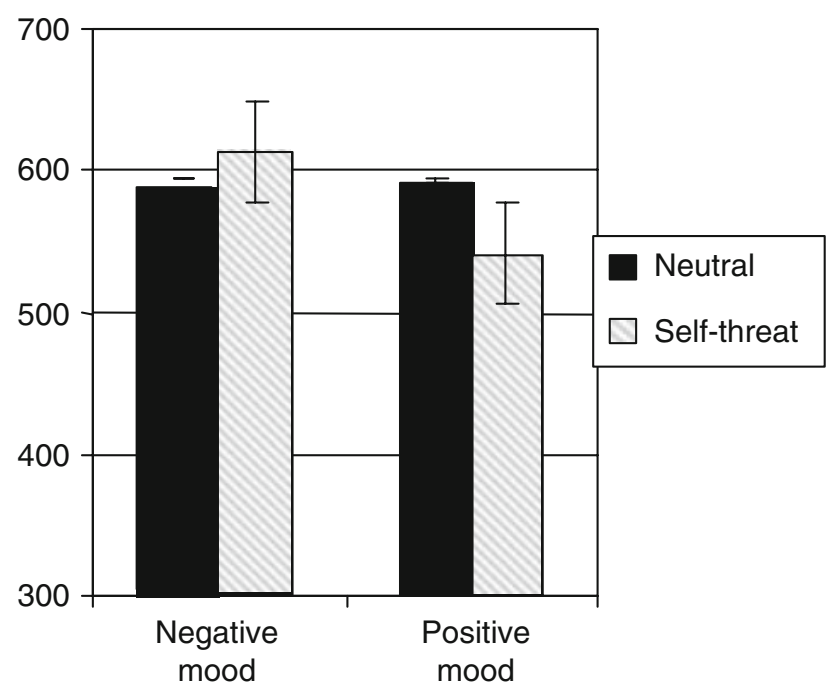

Fig. 1 Interactive effects of mood (negative, positive) and word type (neutral, self-threatening) on response latencies in milliseconds in a Lexical Decision Task (Experiment 2)

each participant. Incorrect responses to target words and neutral words were excluded from the analyses (error rate $=2.87 \%$ ). Our main interest was whether participants in positive and negative moods responded differently to self-threatening words versus neutral words. Thus, the mean response times for self-relevant words and neutral words were subjected to a 2 (mood: negative vs. positive mood) $\times 2$ (word type: self-threatening vs. neutral) mixed design ANOVA with repeated measures on the second factor. This analysis revealed a significant interaction between mood and word type, $F(1,29)=5.41, p<.05$ Simple effects analysis revealed that a positive mood speeded up responses to self-threatening words, $F(1$, $29)=4.32, p<.05$, but not to neutral words $(F<1) .{ }^{1}$ No significant differences in response latencies were observed under negative mood conditions. See Fig. 1.

\footnotetext{
1 The LDT also included three words from the text participants had read that were related to smoking but not necessarily to health risks: cigarette, smoke, and smoking $\left(M_{\text {perceived threat }}=3.21, S D=0.92\right.$ in pilot study). To ascertain that the observed effects were indeed threatspecific, we conducted an ANOVA in which self-threatening words, smoking-related words, and neutral words were entered as a within participants factor, and mood was entered as a between participants factor. This analysis yielded a significant interaction between word type and mood, $F(1,54)=7.29, p<.01$. Simple effects analyses corroborated that response latencies to self-threatening words were faster under conditions of a positive $\operatorname{mood}(M=540, S E=24)$ rather than a negative $\operatorname{mood}(M=613, S E=23), F(1,54)=4.63$, $p<.05$. No significant simple effects of mood were observed for smoking-related words $(M=587, S E=25$ vs. $M=563, S E=25$; $F<1)$ and for neutral words $(M=592, S E=25$ vs. $M=594$, $S E=24, F<1)$
}

Discussion

In the present study, smokers read a health message about the negative consequences of smoking and then responded to self-threatening illness-words, or neutral words in a lexical decision task. As expected, the induction of a positive mood speeded up response latencies to selfthreatening words, but not to neutral words. These findings suggest that the effects of a positive mood may be particularly strong when incoming information poses a direct and relevant threat to the self. This conjecture is further supported by the fact that a positive mood had no effects on response times to smoking-related words, i.e., on self-relevant, non-threatening words. Under negative mood conditions, no differences in response latencies were observed between self-threatening words and neutral words. These findings support the hypothesis that a positive mood better attunes individuals to incoming information that threatens the self. Thus, under positive mood conditions, smokers responded more quickly to words that represented a real threat to their health. The fact that these findings were observed an implicit measure of response latencies suggests that the effects of mood indeed extend to the automatic, intuitive, and non-conscious level.

\section{General discussion}

Two studies tested the effects of mood on the processing and acceptance of potentially self-relevant, threatening health information. It was hypothesized that a positive mood would increase systematic processing of self-threatening health information, and, in addition, increase attendance to selfthreatening information on the implicit level. Under negative mood conditions, individuals were assumed to lack the resources to deal with self-threatening information. Accordingly, a negative mood was hypothesized to induce heuristic processing, and have no effects on implicit attendance to threatening health information. The findings support the hypotheses. In study 1 , a positive mood increased systematic processing only when a health message directly pertained to the self. Under conditions of a negative mood, or low self-relevance, a health message was processed heuristically. In study 2 , a positive mood speeded up smokers' response latencies to threatening information about smoking, but not to self-irrelevant information. Again, no effects were observed under negative mood conditions.

The present findings are a first demonstration that a positive mood can promote systematic processing of 'cold, hard, and self-threatening facts' (Raghunathan and Trope 2002; Trope and Neter 1994). Previous studies have shown that a positive mood can promote the acceptance of selfthreatening information but did not provide conclusive 
evidence regarding underlying cognitive processes. Our findings show that a positive mood increases intensive processing of aversive information only when the information pertains to the self, and suggest that this systematic processing may be prompted by a heightened vigilance toward self-relevant stimuli at the implicit level. Thus, a positive mood may provide individuals with the resources to deal with the psychological costs associated with systematic processing of self-threatening information.

Hence, a positive mood does not necessarily prompt a shift away from the nitty-gritty details of systematic information processing, in pursuit of short-term, hedonic motives (also see Aspinwall 1998; Martin and Davies 1998). Rather, a positive mood increases resources to adapt processing strategies to fit to specific situational requirements (Baumann and Kuhl 2005; Trope et al. 2001). When the "self can afford to do so", i.e. in a situation of low selfrelevance, a positive mood is likely to promote heuristic processing of information. In contrast, when incoming information is relevant to the self, a positive mood is likely to prompt a switch to more systematic processing modes. These findings suggest that the increased attendance to self-threatening information observed in previous studies (Gervey et al. 2005; Trope and Pomerantz 1998) may have its origins at the non-conscious, implicit level. This contends to the notion that the happy self is not dormant as far as information processing is concerned (see also Isbell 2004), but instead has tuned in a 'surveillance mode', that remains active, even nonconsciously.

\section{Self-regulation and health persuasion}

The presently observed effects of a positive mood add to a large body of research on psychological resources that help dealing with self-threatening information. For instance, positive affirmations of the self have been found to increase the acceptance of threatening health information (Harris and Napper 2005; Reed and Aspinwall 1998; Sherman et al. 2000). According to self-affirmation theory (Steele 1988), positive affirmations of the self restore self-integrity on a general level, and consequently functions as a buffer against self-threatening information. Likewise, psychological resources of optimism, personal control and meaning have been found to buffer people against psychological as well as physical adversity (Taylor and Brown 1988; Taylor et al. 2000; Trope et al. 2001). Thus, our findings underscore the pivotal role of positive self-related experiences in balancing psychological threats, and promoting effective self-regulation (see also Fredrickson 2001; Tugade and Fredrickson 2004).

Health campaigns may also benefit from the present findings. Many health education efforts aim to 'shock receivers into persuasion' by conveying graphic depictions and gory details of specific health threats. The assumption underlying these campaigns is that severely threatening health messages force individuals to attend to health information, and change unhealthy behaviors. Recent findings suggest, however, that the effects of emotions and message framing on processing of health messages vary across individuals (e.g., Sherman et al. 2006). The present study adds to these findings by showing that scary health campaigns do not automatically increase message attendance, or systematic processing. Based on the present results, future health campaigns may benefit from creating a subtle balance between emphasizing self-relevance (i.e., vulnerability) and fostering positive moods. Hence, a threatening health message may benefit from the inclusion of positive mood-gaining persuasive elements, such as humor, that help receivers cope with the self-regulatory costs of a self-relevant health threat.

\section{Limitations and future directions}

It was argued that a positive mood promotes attendance to, and systematic processing of self-threatening information, compared with negative mood conditions. Of course, the mood differences observed after our mood manipulations should be viewed as relative, and not absolute. Accordingly, we cannot tell where exactly these mood effects start, and where they will end. For instance, although we did not find any systematic mood effects of the manipulation of vulnerability in the present research, it is hard to verify the overall mood effect of participating in a study about health, or the effect of being presented with false feedback regarding a certain health risk. Hence, the present study provides little insight whether it is the absence of negative moods, the presence of mildly positive moods or extremely positive moods that increases systematic processing of self-threatening facts. This should not be problematic if we view mood itself as a gradual, relative phenomenon, rather than in absolute terms. For instance, few people may be able to achieve a mood state that is actually neutral (with the exception perhaps of some welltrained Buddhist monks). Thus, the present research simply shows that individuals become better at facing 'cold, hard' facts to the extent that they are in better moods.

Second, we have argued that a positive mood may function as a resource to deal with self-threatening facts, quite similar to other psychological resources such as selfaffirmation, and optimism. A question that remains, however, is how a positive mood buffers the costs associated with self-threatening information. Recent findings suggest that a positive mood may promote the integration of information into the self-system, which may serve to downregulate the associated negative affect (Bolte et al. 2003; Koole and Jostmann 2004). These findings fit nicely with the presently observed interaction between self-relevance 
and mood. Specifically, a positive mood should only increase the integration of information into the self-system if the information is actually relevant to the self. This integrative processing may function as a buffer against the psychological costs associated with self-threatening information. Explicit tests of integrative processing following a positive mood constitute an important agenda for future studies. Also, future studies may benefit from including a condition with self-relevant, but non-threatening (e.g., neutral, positive) information as a comparison to self-relevant, threatening information, in order to assess whether the presently observed effects of mood generalize to all self-relevant stimuli regardless of valence.

Finally, it is plausible that there are limits to the presently observed effects of a positive mood. When the incoming information becomes severely and irremediably threatening, a positive mood may cease to be effective in promoting systematic processing of threatening health information. Of interest, recent studies regarding a different self-regulatory resource, i.e. self-affirmation, suggest that the beneficial effects of self-affirmation may be limited to moderate threats, and backfire when threats become very severe (see De Wit et al. 2007). Future studies may want to examine if there are similar limits to the effects of a positive mood in buffering threats to the self.

\section{Concluding comments}

Few people enjoy hearing bad news about some aspect of themselves that they deeply value, whether it concerns their intelligence, social skills, or their health. "I'm not in the mood to deal with this right now", is an often-heard response to selfthreatening information. Indeed, the present findings show that individuals may be too 'tense and nervous to face up to the facts' and, as a consequence, engage in heuristic processing of important information. A positive mood may help overcome such momentary concerns, and promote systematic processing, even if it concerns the ugly truth about oneself.

Acknowledgments We thank Fleur van Noesel and Martijn Boermans for their assistance in conducting the experiments. This research was supported by a Faculty Fellowship granted to the first author by the Center for Comparative Social Studies of VU University, Amsterdam.

Open Access This article is distributed under the terms of the Creative Commons Attribution Noncommercial License which permits any noncommercial use, distribution, and reproduction in any medium, provided the original author(s) and source are credited.

\section{References}

Abele, A. E., Silvia, P. J., \& Zöller-Utz, I. (2005). Flexible effects of positive mood on self-focused attention. Cognition and Emotion, 19, 623-631. doi:10.1080/02699930441000391.
Aspinwall, L. G. (1998). Rethinking the role of positive affect in selfregulation. Motivation and Emotion, 22, 1-32. doi:10.1023/A: 1023080224401.

Baumann, N., \& Kuhl, J. (2003). Self-infiltration: Confusing assigned tasks as self-selected in memory. Personality and Social Psychology Bulletin, 29, 487-497. doi:10.1177/0146167202250916.

Baumann, N., \& Kuhl, J. (2005). Positive affect and flexibility: Overcoming the precedence of global over local processing of visual information. Motivation and Emotion, 29, 123-134. doi: 10.1007/s11031-005-7957-1.

Bless, H., Bohner, G., Schwarz, N., \& Strack, F. (1990). Mood and persuasion: A cognitive response analysis. Personality and Social Psychology Bulletin, 16, 331-345. doi:10.1177/014616 7290162013.

Bolte, A., Goschke, T., \& Kuhl, J. (2003). Emotion and intuition: Effects of positive and negative mood on implicit judgments of semantic coherence. Psychological Science, 14, 416-421. doi: 10.1111/1467-9280.01456.

Clore, G. L., Schwarz, N., \& Conway, M. (1994). Affective causes and consequences of social information processing. In R. S. Wyer \& T. K. Srull (Eds.), Handbook of social cognition (2nd ed., pp. 323-418). Hillsdale, NJ: Erlbaum.

Das, E., De Wit, J. B. F., \& Stroebe, W. (2003). Fear appeals motivate acceptance of action recommendations: Evidence for a positive bias in the processing of persuasive messages. Personality and Social Psychology Bulletin, 29, 650-664. doi:10.1177/01461 67203029005009.

De Hoog, N., Stroebe, W., \& De Wit, J. B. F. (2005). The impact of fear appeals on processing and acceptance of action recommendations. Personality and Social Psychology Bulletin, 31, 24-33. doi:10.1177/0146167204271321.

De Wit, J. B. F., Das, E., \& De Hoog, N. (2007). Self-regulation of health communications: A motivated processing approach to risk perception and persuasion. In K. van den Bosch, M. Hewstone, M. Stroebe, H. Schut, \& J. De Wit (Eds.), The scope of social psychology: Theory and applications (pp. 209-226). Hove, UK: Psychology Press.

Ditto, P. H., \& Lopez, D. F. (1992). Motivated skepticism: Use of differential decision criteria for preferred and nonpreferred conclusions. Journal of Personality and Social Psychology, 63, 568-584. doi:10.1037/0022-3514.63.4.568.

Forgas, J. P. (1995). Mood and judgment: The Affect Infusion Model (AIM). Psychological Bulletin, 11, 39-66. doi:10.1037/ 0033-2909.117.1.39.

Forgas, J. P. (Ed.). (2000). Feeling and thinking: The role of affect in social cognition. New York: Cambridge University Press.

Fredrickson, B. L. (2001). The role of positive emotions in positive psychology: The broaden-and-build theory of positive emotions. The American Psychologist, 56, 218-226. doi:10.1037/0003066X.56.3.218.

Gervey, B., Igou, E., \& Trope, Y. (2005). Positive mood and futureoriented self-evaluation. Motivation and Emotion, 29, 267-294. doi:10.1007/s11031-006-9011-3.

Harris, P. R., \& Napper, L. (2005). Self-affirmation and the biased processing of threatening health-risk information. Personality and Social Psychology Bulletin, 31, 1250-1263. doi:10.1177/01 46167205274694.

Hullett, C. R. (2005). The impact of mood on persuasion: A metaanalysis. Communication Research, 32, 423-442. doi:10.1177/ 0093650205277317.

Isbell, L. M. (2004). Not all happy people are lazy or stupid: Evidence of systematic processing in happy moods. Journal of Experimental Social Psychology, 40, 341-349. doi:10.1016/j.jesp. 2003.06.003.

Isen, A. M. (1999). Positive affect. In T. Dalgleish \& M. J. Power (Eds.), Handbook of cognition and emotion (pp. 521-539). New York: Wiley \& Sons. 
Isen, A. M. (2004). Some perspectives on positive feelings and emotions: Positive affect facilitates thinking and problem solving. In A. S. R. Manstead, N. Frijda, \& A. Fischer (Eds.), Feelings and emotions: The Amsterdam symposium (pp. 263182). Cambridge, NY: Cambridge University Press.

Jemmot, J. B., Ditto, P. H., \& Croyle, R. T. (1986). Judging health status: Effects of perceived prevalence and personal relevance. Journal of Personality and Social Psychology, 50, 899-905. doi: 10.1037/0022-3514.50.5.899.

Koole, S. L., \& Jostmann, N. (2004). Getting a grip on our feelings: Effects of action orientation and external demands on intuitive affect regulation. Journal of Personality and Social Psychology, 87, 974-990. doi:10.1037/0022-3514.87.6.974.

Koole, S. L., \& Kuhl, J. (2003). In search of the real self: A functional perspective on optimal self-esteem and authenticity. Psychological Inquiry, 14, 43-49.

Martin, L. L., \& Davies, B. (1998). Beyond hedonism and associationism: A configural view of the role of affect in evaluation, processing, and self-regulation. Motivation and Emotion, 22, 3351. doi:10.1023/A:1023092508471.

Martin, L. L., \& Stoner, P. (1996). Mood as input: What we think about how we feel determines how we think. In L. L. Martin \& A. Tesser (Eds.), Striving and feeling (pp. 279-301). Mahwah, NJ: Erlbaum.

Martin, L. L., Ward, D. W., Achee, J. W., \& Wyer, R. S. (1993). Mood as input: People have to interpret the motivational implications of their moods. Journal of Personality and Social Psychology, 64, 317-326. doi:10.1037/0022-3514.64.3.317.

Petty, R. E., \& Cacioppo, J. T. (1986). The elaboration likelihood model of persuasion. Advances in Experimental Social Psychology, 19, 123-193. doi:10.1016/S0065-2601(08)60214-2.

Petty, R. E., \& Wegener, D. T. (1999). The elaboration likelihood model: Current status and controversies. In S. Chaiken \& Y. Trope (Eds.), Dual-process theories in social psychology (pp. 41-72). New York: Guilford Press.

Raghunathan, R., \& Trope, Y. (2002). Walking the tightrope between feeling good and being accurate: Mood as a resource in processing persuasive messages. Journal of Personality and Social Psychology, 83, 510-525. doi:10.1037/0022-3514. 83.3.510.

Reed, M. B., \& Aspinwall, L. G. (1998). Self-affirmation reduces biased processing of health-risk information. Motivation and Emotion, 22, 99-132. doi:10.1023/A:1021463221281.

Schwarz, N., \& Clore, G. L. (1996). Feelings and phenomenal experiences. In E. T. Higgins \& A. Kruglanski (Eds.), Social psychology: A handbook of basic principles (pp. 433-465). New York: Guilford Press.

Sherman, D. K., Mann, T., \& Updegraff, J. A. (2006). Approach/ avoidance motivation, message framing, and health behavior: Understanding the congruency effect. Motivation and Emotion, 30, 164-168. doi:10.1007/s11031-006-9001-5.

Sherman, D. A. K., Nelson, L. D., \& Steele, C. M. (2000). Do messages about health risks threaten the self? Increasing the acceptance of threatening health messages via self-affirmation. Personality and Social Psychology Bulletin, 26, 1046-1058. doi: 10.1177/01461672002611003.

Sinclair, R. C., \& Mark, M. M. (1992). The influence of mood state on judgment and action: Effects on persuasion, categorization, social justice, person perception, and judgmental accuracy. In L. L. Martin \& A. Tesser (Eds.), The construction of social judgments (pp. 165-193). Hillsdale, NJ: Erlbaum.

Steele, C. M. (1988). The psychology of self-affirmation: Sustaining the integrity of the self. In L. Berkowitz (Ed.), Advances in experimental social psychology (Vol. 21, pp. 261-302). New York: Academic Press.

Taylor, S. E., \& Brown, J. D. (1988). Illusion and well-being: A social psychological perspective on mental health. Psychological Bulletin, 110, 193-210. doi:10.1037/0033-2909.103.2.193.

Taylor, S. E., Kemeny, M. E., Reed, G. M., Bower, J. E., \& Gruenewald, T. L. (2000). Psychological resources, positive illusions, and health. The American Psychologist, 55, 99-109. doi:10.1037/0003-066X.55.1.99.

Trope, Y., \& Fishbach, A. (2000). Counteractive self-control in overcoming temptation. Journal of Personality and Social Psychology, 79, 493-506. doi:10.1037/0022-3514.79.4.493.

Trope, Y., Hassin, R., \& Gervey, B. (2001). Overcoming defensive feedback seeking: The role of perceives ability and controllability. In A. Efklides, J. Kuhl, \& R. M. Sorrentino (Eds.), Trends and prospects in motivation research (pp. 123-151). Dordrecht, the Netherlands: Kluwer.

Trope, Y., \& Neter, E. (1994). Reconciling competing motives in selfevaluation: The role of self-control in feedback seeking. Journal of Personality and Social Psychology, 66, 646-657. doi: 10.1037/0022-3514.66.4.646.

Trope, Y., \& Pomerantz, E. M. (1998). Resolving conflicts among self-evaluative motives: Positive experiences as a resource for overcoming defensiveness. Motivation and Emotion, 22, 53-72. doi:10.1023/A:1023044625309.

Tugade, M. M., \& Fredrickson, B. L. (2004). Resilient individuals use positive emotions to bounce back from negative emotional experiences. Journal of Personality and Social Psychology, 86, 320-333. doi:10.1037/0022-3514.86.2.320.

Wald, F. D. M. (1984). De verkorte POMS. Master's Thesis. Amsterdam: University of Amsterdam.

Wegener, D. T., \& Petty, R. E. (1994). Mood management across affective states: The hedonic contingency hypothesis. Journal of Personality and Social Psychology, 66, 1034-1048. doi: 10.1037/0022-3514.66.6.1034.

Wegener, D. T., Petty, R. E., \& Smith, S. M. (1995). Positive mood can increase or decrease message scrutiny: The hedonic contingency view of mood and message processing. Journal of Personality and Social Psychology, 69, 5-15. doi:10.1037/ 0022-3514.69.1.5. 